Archivum, LXXI, 2021, pp. 375-401

\title{
Estrategias editoriales de Benegasi y Luján en el periodo de senectute: apuntes sobre tres textos y un retrato
}

\author{
Tania Padilla Aguilera \\ Universidad de Córdoba, Grupo PASO. \\ taniapadillaguilera@gmail.com
}

Recibido: 19/05/2021

Aceptado: 10/09/2021

\section{RESUMEN:}

A lo largo de toda la trayectoria del poeta madrileño José Joaquín Benegasi y Luján (1707-1770), se aprecia el desarrollo de una serie de estrategias literarias y editoriales orientadas a la autopromoción de su propia obra que parecen seguir de cerca el referente vital y literario de Lope de Vega. Estas revelan una temprana autoconcepción de profesionalidad literaria que permite hablar de un comportamiento propio del autor moderno. Sin embargo, es en la etapa última de su trayectoria en la que se aprecia un mayor número de síntomas que apuntan a la utilización premeditada de estas estrategias comerciales. Así lo vemos en la Fama póstuma de fray Juan de la Concepción (1754), la Descripción festiva de las reales funciones... (1770) y Papel nuevo: Benegasi contra Benegasi (1770). Asimismo, el hecho de que encargara un retrato propio para estamparlo en una de las reediciones de sus célebres vidas de santos también puede leerse bajo estos parámetros.

PALABRAS CLAVE: Benegasi y Luján, de senectute, estrategias editoriales, retratística, siglo XVIII. 
Benegasi and Luján's editorial strategies during de senectute period: notes on three texts and a portrait

\begin{abstract}
:
Throughout the entire career of José Joaquín Benegasi y Luján (1707-1770), the development of a series of literary and editorial strategies aimed at the self-promotion of his work can be appreciated, which seem to closely follow the vital and literary reference of Lope de Vega. These reveal an early self-conception of literary professionalism that allows us to speak of a behavior typical of the modern author. However, it is in the last stage of Benegasi's trajectory that we find a greater number of symptoms that point to the premeditated use of these commercial strategies. This is how we see it in the Fama póstuma de fray Juan de la Concepción (1754), the Descripción festiva (1770) and Papel nuevo: Benegasi contra Benegasi (1770). Likewise, the fact that he commissioned his own portrait to stamp in one of the reissues of his famous lives of saints can also be read under these parameters.
\end{abstract}

KEYWORDS: Benegasi y Luján, de senectute, editorial strategies, portraiture, $18^{\text {th }}$. century.

\title{
1. Introducción
}

En el estudio de la trayectoria del poeta madrileño José Joaquín Benegasi y Luján (1707-1770), sería interesante plantear la existencia de una etapa autónoma y bien diferenciada que, utilizando el término que Rozas (1990) aplica a la trayectoria lopesca, podríamos denominar de senectute. Al igual que en otros autores, esta etapa coincidiría con la parte final de su periplo vital y literario (Padilla Aguilera 2021) ${ }^{1}$. Sin embargo, si atendemos al cambio de estrategia literaria, podemos decir que en Benegasi esta etapa

1 Este trabajo se inserta en el Proyecto Coordinado "Sujeto e institución literaria en la edad moderna" (FFI201454367-C2-1-R), que actualmente tiene su continuidad en el subproyecto "Biografías y Polémicas: Hacia la Institucionalización de la literatura y el autor" (RTI2018-095664-B-C21), ambos dirigidos por Pedro Ruiz Pérez (Universidad de Córdoba). Los resultados de esta parte de la investigación deben mucho a varias fructíferas sesiones de trabajo con el profesor Gabriel Sánchez Espinosa (Queen's University Belfast) durante una estancia realizada en el mes de junio de 2019. Sigo su metodología y planteamientos, desarrollados en trabajos como Gabriel Sánchez Espinosa 2009. 
de senectud comenzaría en torno a la mitad de los años 50, cuando el autor ronda también la cincuentena.

En estos años, el poeta madrileño lleva a cabo una serie de iniciativas con resultados fructíferos que demuestran la seguridad con la que se mueve a estas alturas en el mercado editorial de la época. Aunque algunas de estas iniciativas se presentan como iniciales tanteos en los comienzos de su trayectoria, no es hasta bien entrada la década de 1750 cuando las desarrolla de forma sistemática. Estas iniciativas, cuya premeditación hace de ellas pequeños hitos en la carrera literaria de Benegasi, se convierten en síntomas de esa etapa de madurez cuya característica más evidente es la conquista de una posición firme en el campo literario (Bourdieu 2006) que concede al autor una mayor libertad expresiva. Algunos de estos indicios que tienen que ver con un perfil más profesionalizado son los siguientes:

a) La consolidación de una firma personal, que en la mayoría de los casos aparece acompañada de unas credenciales fijas. Después de un periodo inicial de enmascaramiento de la firma mediante el uso de seudónimos ${ }^{2}$ más o menos relacionados con su nombre real (Padilla Aguilera 2019b, 528-529), el autor estabiliza el uso de una firma reconocible por el lector: "José Joaquín Benegasi y Luján". A continuación de esta desarrolla, en las portadas de sus obras, sus méritos y cargos: "señor de Terreros y Valdeloshielos", que suele aparecer en los textos de una etapa intermedia, y el siempre presente "regidor perpetuo de la ciudad de Loja". En las publicaciones a partir de 1763, cuando se ordena sacerdote, las credenciales se hipertrofian incluso dando lugar a cambios en las portadas de las reediciones (Padilla Aguilera 2019b, 538-539): "canónigo reglar de nuestro gran padre san Agustín, del hábito de san Antonio Abad". A veces estas se acortan mediante un "etc.", aunque es más frecuente

2 Acerca del uso del seudónimo como parte de la estrategia autorial de los autores de este período, véase Deacon 1999. 
que esta abreviatura aparezca a continuación de todos los cargos, dando a entender que estos son solo un resumen. Esta firma compleja arroja una información sobre el autor orientada a la construcción de un determinado perfil que se puede resumir con las categorías profesional, noble, funcionario, sacerdote.

b) Las reediciones, que son un claro síntoma del éxito de ventas. En el caso de Benegasi, aparecen principalmente asociadas a las vidas de santos que publicó en los años 50 y que conocieron reimpresiones posteriores (Benegasi y Luján 1750, 1752, 1752b, 1763, 1763b, 1779). Estas tienen lugar tanto en los años próximos a la publicación de la obra, lo que evidenciaría el agotamiento de una edición que se seguía demandando, como a partir de la ordenación sacerdotal del autor, que permite al editor un relanzamiento del producto bajo unas nuevas credenciales que repercutirían de forma directa en el contenido de la obra (Lopez 2003). Además, estas obras también se reeditan una vez muerto el poeta, lo que determina que la imagen post mortem de Benegasi quede vinculada a esa poesía que, aunque escrita en seguidillas y de estilo jocoserio (Étienvre 2004, Mata Induráin 2018), tiene un carácter religioso más acorde con los últimos años de sacerdocio del poeta (Padilla Aguilera 2019b, 538-539).

c) La aparición de ediciones completas de sus poesías, que van creciendo progresivamente con un afán colectivo/recapitulativo y que apuntan a una concreta idea de fama relacionada con un legado ordenado que prioriza la intervención de la voluntad del autor en la recepción de su obra. Ya en 1743, el autor publica sus Poesías líricas (Benegasi y Luján 1743), que se reeditan en 1752 junto a la Vida del glorioso san Dámaso, y en torno a 1760 junto a obras nuevas y un retrato del autor con el título Obras métricas que a distintos asuntos... (Benegasi y Luján 1760?), iniciativa a la que habría que sumar la publicación de las 
Obras líricas jocoserias (Benegasi y Luján 1746), en la que reedita sus composiciones junto a las de su padre.

d) El desarrollo de calculadas incursiones en el ámbito del teatro con el cultivo del entremés ${ }^{3}$ y la comedia, en algunos casos con reediciones, como la de la Comedia (que no lo es) burlesca... (Anónima s.f.; Benegasi y Luján 1761; Mata Induráin, ed. 2007). Esto apunta a la exploración de nuevos circuitos profesionales desde una posición cauta, de tanteo, que oscila entre el amateurismo y la profesionalidad.

e) Un incremento de la publicación de textos circunstanciales dedicados a eventos de cierta importancia social o dirigidos a nobles y eclesiásticos relevantes o a miembros de la familia real. Es el caso de la Descripción del terremoto (Benegasi y Luján 1755b) o del Papel en prosa y diferentes metros (Benegasi y Luján 1755c), dedicado al marqués de la Olmeda. Ambos conocieron diferentes versiones [dedicó un segundo texto al terremoto (Benegasi y Luján 1755)] y reimpresiones (Benegasi y Luján 1760?b). Este tipo de textos, reveladores de un comportamiento que podría encuadrarse dentro de las formas clásicas de mecenazgo (Lefevere 1997, 31), son utilizados por Benegasi como parte de una estrategia en paralelo a las aún incipientes pautas por las que se rige el nuevo mercado. Aunque el poder de los mecenas ya no es el de la centuria anterior, a Benegasi le conviene tener a su favor al nuevo monarca, a los nobles más poderosos y a los escritores más influyentes de la corte. Por otra parte, escribir sobre los hechos inmediatos, sobre el presente, aproxima

3 Benegasi escribió un entremés titulado "La campana de descasar" (Benegasi y Luján 1746) que no consta en el estudio bibliográfico de Pedro Ruiz Pérez (2012). En relación con esta pieza, véase la edición comentada de Carlos Mata Induráin (2018), quien asimismo ha publicado recientemente varios trabajos y ediciones de gran solvencia que contribuyen a la recuperación de la producción dramática de este autor. 
la labor del poeta al periodismo, ese subgénero que nace y se abre paso con fuerza a medida que avanza el siglo.

A pesar de que, ya desde los albores de su carrera literaria, Benegasi comienza a desarrollar algunas estrategias que dan lugar a toda esta sintomatología del escritor profesional, no es hasta la etapa final de su trayectoria cuando se desarrollan de una manera más evidente y sistemática. Desde el punto de vista del contenido, en esta etapa Benegasi exacerba sus rasgos de estilo (arte menor, tono jocoserio) y adquiere un discurso que, con todas las salvedades, podríamos considerar más "sincero" $\mathrm{o}$, por lo menos, más personal (numerosas referencias metaliterarias, fuerte presencia del yo e inclusión de datos autobiográficos concretos), lo cual es a su vez síntoma de la adquisición de una identidad propia en el campo literario.

De todas las obras que podrían encuadrarse en esta etapa de senectute, cabría destacar tres lo suficientemente distanciadas, pero también lo suficientemente vinculadas entre sí como para que un análisis comparativo entre ellas permita extraer una serie de conclusiones. Estas son la Fama póstuma de fray Juan de la Concepción (Benegasi y Luján 1754), la Descripción festiva (Benegasi y Luján 1760), y Benegasi contra Benegasi (Benegasi y Luján 1760b, 2015) ${ }^{4}$.

Los aspectos más materiales del texto impreso condicionan la lectura influyendo en multitud de factores, como el público al que se dirige la obra, la disposición del lector ante ella o la manera en que se asimila su contenido; a esto cabría añadir el impacto que tienen sobre el proceso escritural (McKenzie 1986). Por otra parte, ese mencionado carácter personal que caracteriza a las obras de esta etapa, con cierto marchamo de lo que, con todas las salvedades, podemos calificar de "sinceridad", se traduce en una marcada autorreferencialidad a la que también se añade un fuerte componente metaliterario.

4 Desde otro enfoque al aquí planteado, que, sin embargo, resulta complementario, estas obras han sido abordadas con anterioridad en los siguientes trabajos: Padilla Aguilera 2019, 2021b y 2023 (en prensa). 
En este trabajo, al breve cotejo de las tres obras de senectute mencionadas, voy a añadir el análisis de un retrato del autor, el único que se conserva: un grabado de Jerónimo Antonio Gil que aparece en la ya referida edición de sus Obras métricas (Benegasi y Luján 1760?). La idea es corroborar mediante estos ejemplos los puntos expuestos al inicio de la investigación.

\section{El Parnaso, la fiesta y la polémica}

La Fama póstuma, la Descripción festiva y Benegasi contra Benegasi son tres obras muy diferentes que, sin embargo, guardan muchas similitudes entre sí. Veremos brevemente las principales características de cada una de ellos con el objetivo de analizar su encaje en la etapa de senectute del autor.

La Fama póstuma de fray Juan de la Concepción (1754) es un homenaje a un ilustre difunto concebido en parte como otras famas $^{5}$, en parte como las clásicas recopilaciones poéticas ${ }^{6}$. Fray Juan de la Concepción (1702-1753), popularmente conocido como «el Monstruo» tanto por su talento como por su ingente producción poética, ocupó varios cargos relevantes a lo largo de su trayectoria, entre los que destaca el de jefe de la Suprema de la Inquisición, tal y como consta en la portada de la Fama que le dedica Benegasi.

El texto se editó en $4^{\circ}$, con particular esmero en la dispositio textual (texto ordenado, con numerosos adornos) y en la composición de los materiales (calidad del papel y de la cubierta, en pergamino), a pesar de los tiempos de producción, que fueron muy breves (el carmelita falleció en 1753 y su Fama vio la luz tan solo unos meses más tarde). Por estas características, el destinatario ideal de la obra bien podía ser un lector culto, en muchos

5 En la estrategia seguida por Benegasi con la Fama póstuma que dedica a su amigo fray Juan de la Concepción en 1754 no podemos olvidar el claro referente de la Fama póstuma que Pérez de Montalbán dedica a su admirado Lope en 1636.

6 Entre las más conocidas estaba la Primera parte de las flores de poetas ilustres (Espinosa 1605). Pedro de Espinosa realiza su antología movido por una concreta intencionalidad estética, pero también con el objetivo de constituir y delimitar un determinado grupo de autores entre los que se incluye. 
casos también poeta. A los obligados paratextos legales, le sigue un nutrido corpus de paratextos literarios. Estos conforman un elaborado pórtico de entrada en el que se dan cita un gran número de firmas contemporáneas, la mayoría de ellas pertenecientes al bullicioso campo literario del Madrid de la época, en el que se insertaban tanto el homenajeador como el homenajeado.

En este sentido, abundan los autores de perfil religioso (fray José de san Jacinto, fray Lucas Carrasco), así como del mundo funcionarial (José Figueroa, Antonio Merano y Guzmán) o militar (José Pinel Ladrón de Guevara), espacios todos ellos en los que se movió fray Juan, que ocupó numerosos cargos políticos y religiosos. Asimismo, entre los autores concitados, encontramos también a algunos nobles (marqués de la Olmeda, Francisco Scotti o Francisco Monsagrati), junto a otros autores cuyo perfil es marcadamente profesional (Torres Villarroel).

Con esta variada nómina Benegasi propone una selecta república literaria en la que predominan dos factores: la avanzada edad de sus miembros y su gusto por una estética preponderantemente barroca. Esta idea es refrendada, además, por el texto inédito de fray Juan que Benegasi escogió para editar junto a su Fama: la "Escuela de Urania", un espejo de príncipes que rezuma un barroquismo de clara raigambre gongorina y propósito didáctico, en la línea en la que trabajaron los llamados "novatores" (Maravall 1966; Pérez Magallón 2002). Además, este texto aparece precedido de un extenso poema en octavas titulado "Fama póstuma" en el que Benegasi da rienda suelta a su particular estilo conceptista, preponderantemente basado en dilogías y juegos de palabras. Cierra la obra una nómina en la que se recogen los textos publicados por fray Juan; tras esta, Benegasi, elocuentemente, aprovecha para incluir la lista de sus propias publicaciones.

En definitiva, con la Fama póstuma de fray Juan de la Concepción, Benegasi se sirve del homenaje a fray Juan, a quien le unió una amistad profunda, para llevar a cabo un movimiento estratégico en el campo literario de su época mediante el que persigue posi- 
cionarse en la república literaria de su tiempo atendiendo a unas coordenadas muy precisas.

La Descripción festiva (1760) es un poema en seguidillas compuestas que describe de forma paródica las fiestas que se celebraron en Madrid al año de la llegada al trono de Carlos III. En esta ocasión, nos encontramos ante un claro ejemplo de lo que en el siglo xviII se denomina papel, que es el sustituto del pliego suelto: no presenta paratextos legales, la edición no está muy cuidada (sin encuadernar, distribución del texto principal en dos columnas; por eso, algunos de los ejemplares conservados han llegado hasta nuestros días en volúmenes facticios). El extenso poema de la "Descripción festiva", formado por 2462 versos, está precedido de un prólogo en el que el autor plantea cuestiones de carácter metapoético relacionadas con el uso del estilo jocoserio y su intencionalidad o con la posible recepción de la obra por parte del público. Concluye este con unas octavas en las que el poeta, con el firme propósito de defender su singular enfoque literario a la hora de abordar unas fiestas en honor de los monarcas, se enfrenta a Talía, la musa de la comedia, quien no se muestra demasiado cómplice.

A lo largo del poema central de la obra, Benegasi va describiendo la carrera de las fiestas atendiendo de forma particular a las casas de los nobles y de los religiosos, a través de las cuales lleva a cabo una explícita sátira de esta parte de la sociedad madrileña. También las clases bajas son criticadas, sobre todo durante el relato de la fiesta de los toros. A lo largo de su obra, como en otras ocasiones, se sirve de figuras como la dilogía o la metáfora para enmascarar la crítica. En este sentido, el característico estilo jocoserio le permite moverse en un espacio de ambigüedad que resulta desconcertante. Además, el autor está presente a lo largo de toda la composición, tanto a través de un uso constante de la primera persona como de la introducción de comentarios críticos, a modo de excursos, de carácter fuertemente subjetivo. Así pues, siguiendo el tópico del ut pictura poiesis, el autor traza una panorámica del recorrido en la que alterna recursos de la 
crónica periodística (siguió muy de cerca la publicada en la Gaceta de Madrid con fecha de 22/07/1760, n.. 30: Vv. Aa. 2021, 242$248^{7}$ ), la descripción de fiestas de raigambre barroca y la sátira de estados.

El soneto que cierra la obra, de tono serio y ditirámbico, parece querer salvar a los monarcas de la crítica, a quienes pasa revista -de forma bastante decorosa: se limita a describir la fastuosidad de coches y vestidos- en la pormenorizada descripción del Te Deum que tuvo lugar en la iglesia de Los Jerónimos durante las jornadas celebrativas.

En definitiva, con la Descripción festiva Benegasi utiliza un molde propio de las pautas de mecenazgo imperantes en los siglos anteriores para llevar a cabo un personal ejercicio literario en el que, al tiempo que afirma su personalidad literaria, desafía las normas sociales con la impunidad de un bufón de la corte.

Finalmente, Benegasi contra Benegasi (1760) es un nuevo papel, de extensión mucho más reducida (28 páginas, las 6 primeras sin numerar), que se publica a los pocos meses del anterior como defensa o justificación ante las críticas recibidas, que debieron de circular de forma oral o manuscrita, puesto que no hemos tenido constancia de ellas. En este nuevo texto, Benegasi hace un ejercicio dialéctico de desdoble para contraponer sus dos facetas: la de poeta y la de crítico. Se trata de una obra compleja, que adopta una hipertrofiada forma epistolar en la que el autor intercala composiciones poéticas en un enfrentamiento consigo mismo. La valentía de llevar su apellido al título se confirma a lo largo del texto, en el que exhibe un discurso que alterna el orgullo autorial con una madura autocrítica con la que intenta proyectar una imagen de autor divertido y popular, alejado tanto del ámbito académico como religioso. Así pues, mediante este texto el autor se reafirma en su propuesta anterior desarrollando pormenorizadamente los argumentos que constituyen la base de su poética personal.

7 https://www.boe.es/datos/pdfs/BOE//1760/030/A00242-00248.pdf (última consulta 10/12/2021). 
Como vemos, se trata de tres obras muy distintas que incluso podrían encuadrarse en diferentes subgéneros. Sin embargo, podemos decir que en todas ellas la circunstancia juega un papel primordial. En la Fama póstuma, en la medida en que reconstruye parcialmente una red literaria a modo de homenaje tras la muerte de uno de sus integrantes; en la Descripción festiva, por el acontecimiento social relatado, cuya actualidad y relevancia lo hizo ocupar decenas de páginas en los periódicos de la época, y en Benegasi contra Benegasi porque es un texto que surge como reacción a una polémica literaria suscitada por otro. Este estrecho diálogo con la circunstancia evidencia tanto la conexión, buscada o no, del autor con su presente, como la rapidez de los tiempos escriturales, que es una consecuencia directa de la inmediatez de la imprenta ${ }^{8}$.

Este vínculo de las tres obras con la realidad las circunscribe de forma particular al contexto en el que surgen. Esto dificulta la comprensión actual de estos textos, que en su edición necesitan de una particular iluminación que ponga el foco de forma primordial sobre los espacios, los personajes o las circunstancias abordadas. Sin embargo, esta particularidad, que a priori pudiera disuadir al estudioso de abordar la edición de los textos de Benegasi, se convierte en una de las razones por las que merece la pena que su obra sea editada de nuevo'.

Por otra parte, el hecho de que la mayor parte de la producción poética de Benegasi apunte significativamente hacia la circunstancia en la que se inscribe la convierte en una producción de singular relevancia para el conocimiento del contexto sociocultural de esta época. Además, el singular perfil del autor (profesional, reconocido en su época, pero de trayectoria limitada en

8 A propósito del funcionamiento de la imprenta y los tiempos de impresión en esta etapa de nuestras letras, resultan fundamentales los estudios de Jaime Moll (1994) y Víctor Infantes (2006).

9 Actualmente, tengo pendiente de publicación una edición conjunta modernizada y anotada de la Descripción festiva y Benegasi contra Benegasi, y la edición de la Fama póstuma se encuentra en proceso de corrección de cara a una edición futura. 
lo que respecta a su recepción posterior) lo ubica en un espacio de normalidad, de medianía, que es el adecuado para una reconstrucción más realista y ecuánime de esta etapa de nuestras letras.

El hecho de que en esta parte final de la trayectoria de Benegasi encontremos tres obras estrechamente vinculadas a la circunstancia -y no son las únicas: la inmensa mayoría de ellas lo está- es sintomático tanto del general gusto de la época como del desarrollo de determinados procedimientos intrínsecos a la propia trayectoria del autor, que a estas alturas de su carrera literaria se puede permitir mirar de forma más directa hacia unos círculos literarios que conoce bien y de los que se siente parte, hacia la nueva corte en formación y los eventos vinculados a ella, o hacia unos lectores y unos críticos cuya opinión ya conoce lo suficientemente bien como para formular su réplica de antemano (al margen de que, en efecto, existieran unas críticas previas).

En definitiva, en esta etapa de senectute, encontramos tres textos que, además de por su marchamo de "sinceridad", se caracterizan por su fuerte vínculo con el presente que los ve nacer -lo cual también es particularmente frecuente en los textos humorísticos o paródicos, que son los habituales registros en los que se mueve Benegasi- y por sus numerosas referencias metatextuales, que también activan la singular circunstancia de los cotextos. Esta metarreferencialidad, que se incrementa en las obras de esta etapa, es fruto de varias décadas de reflexión personal sobre la propia voz poética y el espacio que ocupa el autor en el contexto literario de su época, esto es, sobre la autoconcepción personal de José Joaquín como Benegasi, ese autor que, en Benegasi contra Benegasi, invade el título de su obra en letras de una tipografía de gran tamaño.

\section{Benegasi frente al espejo: el modelo de Lope}

A continuación, examinaré el único retrato que conocemos del autor. Como ya he planteado con anterioridad (Padilla Agui- 
lera 2021), en Benegasi encontramos una imagen de senectute bastante similar a la de Lope: un autor ya consagrado que llega al sacerdocio tras enviudar en más de una ocasión y perder a un hijo con las consiguientes secuelas emocionales (Padilla Aguilera 2019c, 392-394). Los retratos de ambos en esta época invitan a un elocuente cotejo que no podemos obviar.

En torno a 1760, Benegasi publica sus Obras métricas (Benegasi y Luján 1760?). El carácter compilatorio o recapitulativo de esta obra la convierte en una buena opción para que se publique acompañada de un retrato del autor. Como ya sabemos, Lope fue incorporando retratos propios en sus obras a partir de la primera edición de La Arcadia (Vega Carpio 1598), aunque es en el Laurel de Apolo (Vega Carpio 1630) donde encontramos una imagen que se ajusta más fielmente a la de estos últimos años de madurez ${ }^{10}$.

Este retrato, firmado por el grabador Juan de Courbes (c. 1592-1641), contrasta con la imagen del Lope cortesano de sus años de juventud y recupera la imagen del sacerdote ordenado en Toledo en 1614. Al final de su vida, Lope conseguiría el título de "frey" y entraría a formar parte de la orden de san Juan. Este grabado, que es uno de los más conocidos, se reeditará en varias ocasiones (Lucía Megías 2013 ${ }^{11}$ ), entre ellas, en el Peregrino en su patria (Vega Carpio 1604; 1733 reed.), lo que lo convierte en un referente bastante próximo a Benegasi. Pese a sus evidentes diferencias, son considerables las similitudes entre ambos retratos:

10 A propósito de los retratos de Lope, véase Lafuente Ferrari (1935), y los trabajos, más recientes, de Antonio Sánchez Jiménez (2006 y 2011).

11_http://www.memoriademadrid.es/buscador.php?accion=VerFicha\&id=118196 (última consulta: 19/05/2021). 


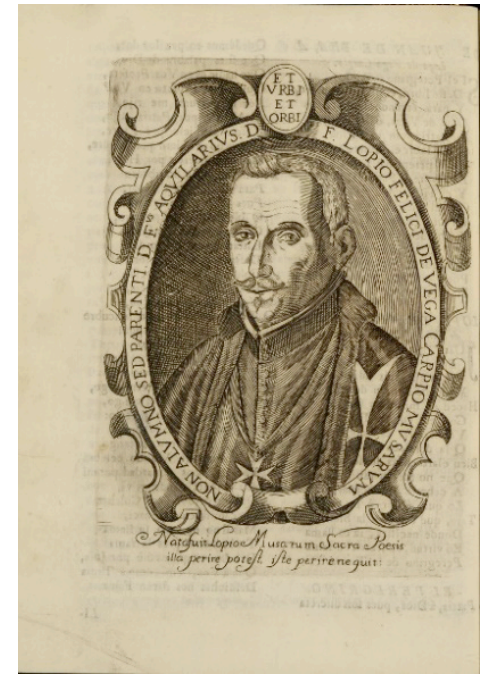

Fig. 1: Retrato de Lope de Vega (1630)

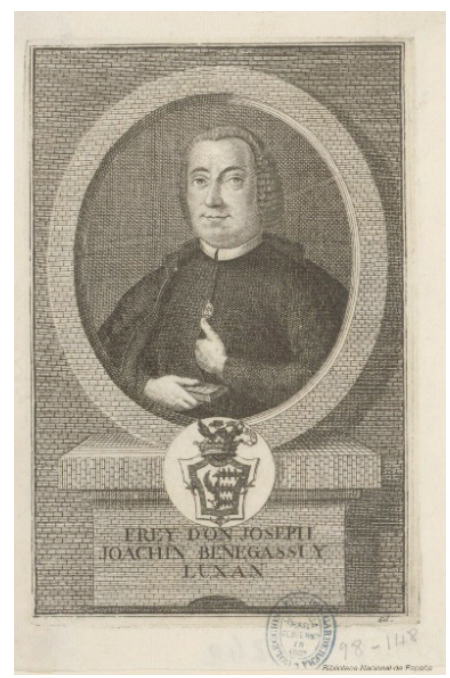

Fig. 2: Retrato de Benegasi y Luján (1760)

Los dos autores son retratados con la vestimenta sacerdotal, en posición de tres cuartos, denotando cierto aplomo vinculado a la edad avanzada, asumido el peso de una trayectoria ya desempeñada y con el gesto adusto, aunque Benegasi luce una tenue mueca irónica más acorde con el tono de su poesía. Ambos aparecen enmarcados en una especie de orla o medallón. A propósito de este tipo de represenciaciones, afirma Buiguès $(2019,13)$ :

El siglo XVII marca una ruptura en la que, seguramente por el peso de la nueva modalidad de representación del autor en un medallón, la imagen del autor en su actividad redaccional disminuye. En cambio, en el siglo XVIII se produce un aumento notable de esta imagen, hasta casi el $40 \%$ del total. Sin valor definitivo, estos porcentajes reflejan evoluciones interesantes. En particular, el aumento en el siglo XVIII parece evidenciar una imagen más profesionalizada del autor de la que la que suele representarlo en su espacio de trabajo, el gabinete/biblioteca. 
Mientras que el retrato de Lope es uno más de la larga lista de grabados que se incorporaron a sus libros, el de Benegasi es, sin embargo, el único que existe del autor, y fue incorporado a un impreso ya al final de su trayectoria profesional ${ }^{12}$. Es obra de Jerónimo Antonio Gil (1732-1798), reconocido grabador, tallista y pintor. Se formó con el grabador Tomás Prieto y completó sus estudios con el escultor Felipe de Castro y con el pintor Luis González Velázquez. Muy pronto destacó como medallista y grabador de láminas, concretamente de monedas y monumentos antiguos. En 1767 la Real Academia de la Historia le encargó grabar las monedas y epígrafes árabes que la institución había reunido y tenía previsto publicar. En 1778 lo nombraron primer grabador de la Real Casa de la Moneda de México con el encargo de establecer una escuela de grabado y mejorar las acuñaciones de la ceca. Gil continuó su carrera profesional en México, donde dejó algunas obras, entre las que destacan las medallas de proclamación de Carlos IV y la de la estatua ecuestre que se colocó en la plaza mayor de México (Maier Allende 2018 ${ }^{13}$ ).

El retrato de Benegasi tuvo que ser un encargo personal del autor anterior a 1760, cuando Gil estaba aún en Madrid. Por esas fechas, el grabador se distanció de su maestro y se vio obligado a trabajar haciendo retratos a particulares, la mayor parte de ellos escritores.

La estampa original, que se conserva en la Biblioteca Nacional $^{14}$, tiene unas dimensiones de $153 \times 103$ mm. En ella Benegasi aparece vestido de sacerdote y enmarcado por una clásica mandorla sobre un pedestal. Tanto esta estructura como el fondo sobre el que se sitúa imita la apariencia del ladrillo o el sillar pétreo, con lo que se remite a lo macizo y duradero, a lo arquitectónico. En la intersección entre la mandorla y el pedestal, figura un es-

12 Para el análisis del retrato del autor, sigo muy de cerca los trabajos de Álvarez Barrientos (2006), Molina Martín (2016), Buiguès (2019) y Cárdenas Luna (2019).

13 http://dbe.rah.es/biografias/21967/jeronimo-antonio-gil (última consulta: 10/12/2021).

$14 \mathrm{IH} / 1055$. También se conserva una fotografía con fecha de 1907(?) en papel gelatina de 238x180 mm. (JIN/6/159). 
cudo de armas que subraya el carácter nobiliario del personaje. Benegasi porta en el retrato un pequeño libro en la mano derecha que bien podría ser un breviario; la mano izquierda la tiene colocada a la altura del pecho, en una pose que también dialoga con otros retratos históricos, pero que apunta asimismo a una posible actitud de sinceridad y/o recogimiento espiritual. Su figura es oronda, y la cabellera, aunque parece natural, recuerda con sus rizos a las pelucas de la época y, en concreto, a la vinculada a la carrera jurídica, que era la profesión inicial del autor. Su gesto es tranquilo y en él se refleja más aplomo que soberbia, con lo que parece apuntar a esa idea del poeta pobre y retirado, cultivador de una rural aurea mediocritas que Benegasi asociaba en sus textos a la Loja de la que se nombraba «regidor perpetuo».

No obstante, pese a sus singulares características y a las apuntadas conexiones con el retrato de Lope en su última etapa, no debemos perder de vista las conexiones de este retrato con otros grabados elaborados por Jerónimo Antonio Gil en esta etapa, bastante similares entre sí, como es el caso de los que hizo del conde de Gálvez, Ambrosio de Morales y Enrique Flórez, entre otros. Asimismo, debemos encuadrar el retrato de Benegasi en una tradición retratística particularmente fructífera durante el siglo xviII. Álvarez Barrientos (2020) se ocupa especialmente del retrato de los poetas en relación con la producción astrológica (almanaques y pronósticos), de la que Benegasi también participó $^{15}$. Acerca del retrato dieciochista, afirma:

Como se sabe, en la época se produce un gran desarrollo de este tipo de retratos entre escritores, científicos, artistas, ajustado a ciertas convenciones que antes habían servido principalmente para mostrar a la aristocracia. López de Sedano en su Parnaso español (1768-1778) incorpora siempre que puede los retratos de los escritores antiguos que edita, como forma de distinción y reclamo,

15 Con su obra Pronóstico el más cierto y más breve que en estilo jocoso hace del nuevo cometa don Juan del Rosal en este romance. Madrid: Juan de San Martín [...] s.f., firmada bajo el seudónimo "Juan del Rosal". 
mientras Feijoo, Mayans, el padre Isla, Sarmiento, Moratín, Iriarte, la mayoría de los escritores de la época, se hacen retratar. Solían aparecer todos como burgueses, ataviados con sus mejores galas, o como profesionales con aquellos elementos iconográficos que identificaban sus actividades (Álvarez Barrientos 2020, 70).

En el caso de Benegasi nos encontramos ante un retrato que, además de encuadrarse dentro de estas tendencias generales señaladas entre los autores dieciochescos, entra en estrecho diálogo con la obra junto a la que se edita y a la que fue incorporado por interés personal del propio poeta (queda pendiente de examinar si en todos los ejemplares o solo en algunos). En este sentido, refleja una imagen completa, total, de Benegasi, con la que este deseaba ser reconocido y perdurar, esto es, alcanzar la fama. Además, en el contexto dieciochesco, con el Parnaso de Sedano a la cabeza, comienzan a imprimirse series biográficas en propuestas antológicas, es decir, compilaciones de autores en las que, junto a sus textos, se incluyen sus biografías y retratos, formando ramillete. Así, se configuran una suerte de macroantologías de autores españoles en las que la imagen de autor comienza a contemplarse desde la colectividad del canon. No podemos descartar que en el proyecto socioliterario y vital de Benegasi estuvieran particularmente presentes estos referentes de la historiografía de la literatura a la hora de hacerse retratar. En esta línea, nuestro poeta buscaría plasmar su imagen, además de para que esta se publicara acompañando a su obra, de cara a los futuros parnasos en los que pudiera ser integrada. Esta idea del retrato propio dialogaría con los presupuestos que hicieron posible la Fama póstuma.

En cualquier caso, esta estampa del poeta es el colofón necesario, y desde luego perfectamente coherente y esperable, a una trayectoria profesional en la que la autorreflexión y cierta tendencia a una explícita sinceridad logran trazar un nítido perfil de autor. En su estrategia, Benegasi, de forma premeditada y asumiendo el control absoluto de la impresión, incluso la de la 
propia imagen que acompaña a sus poemas, hace converger su perfil personal y profesional. A pesar del referente lopesco en la estrategia, la emancipación de Benegasi es clara. Esta es lograda principalmente a partir de la conquista de una voz personal que se manifiesta en los tres textos escogidos de esta pronta etapa de senectute.

El paralelismo literario y vital entre Benegasi y Lope es tan estrecho que a veces es imposible pensar que no sea pretendido. En los tres textos tomados como ejemplo este se evidencia de forma muy particular. En el caso de la Fama póstuma resulta inevitable la comparación con el mencionado Laurel de Apolo, en el que Lope también traza un detallado mapa literario pro domo sua. Las conocidas pretensiones de acercamiento a la corte de Lope encuentran su eco en la velada estrategia de Benegasi con la Descripción festiva en el contexto de cambio monárquico (Sánchez Jiménez 2018). Finalmente, la diatriba literaria que dota de sentido a Benegasi contra Benegasi recuerda a las polémicas mantenidas por Lope a lo largo de toda su carrera literaria, entre las que podríamos destacar el enfrentamiento con Pellicer con motivo del controvertido asunto de la estética gongorina (Rozas 1984) o, ya en el periodo final de su trayectoria, con Diego de Colmenares (Tubau 2007); ambas dieron lugar a un ingente intercambio de carácter metaliterario.

\section{Conclusiones}

El desarrollo por parte de Benegasi de una serie de estrategias editoriales específicas durante la etapa final de su trayectoria profesional nos hace ver en ella un signo propio identificable con el periodo de senectute, que se caracteriza por el incremento de la sinceridad, por la exacerbación de una voz propia y por el alarde de la firma, que encuentra su epítome en la incorporación del retrato personal a su obra poética. En su retrato se recogen y fijan todas sus facetas en una imagen sincera y definitiva, despojada de todas las máscaras al tiempo que portadora de todas ellas a la vez: la más adecuada para la ansiada fama futura. 
Bajo estas premisas iniciales decidí abordar el estudio en profundidad de tres obras fundamentales de esta etapa, de las que en este estudio se ofrece un breve cotejo: la Fama póstuma, la Descripción festiva y Benegasi contra Benegasi, tres textos que, pese a nacer bajo un mismo impulso literario, son muy distintas entre sí. Se trata de tres obras dirigidas a públicos muy diferentes con las que Benegasi logra aprovechar pro domo sua esa circunstancia a la que están tan vinculadas. En la Fama póstuma Benegasi se define en función de sus colegas, con lo que baliza su posición en el campo literario de la época; en la Descripción se sitúa en relación con el pueblo madrileño ante la circunstancia de la llegada al trono de los nuevos monarcas y la configuración de la reciente corte, y en Benegasi contra Benegasi se posiciona frente a sí mismo, sometiéndose a un proceso casi catártico de mordaz -pero también autocondescendiente- crítica literaria.

\section{Bibliografía}

Álvarez Barrientos, J. (2006) Los hombres de letras en la España del siglo XVIII. Apóstoles y arribistas, Madrid, Castalia.

Állvarez Barrientos, J. (2020) El astrólogo y su gabinete. Autoría, ciencia y representación en los almanaques del siglo xviII, Anejos de Cuadernos de Estudios del Siglo XvIII, 4.

Benegasi y Luján, J. J. (1743) Poesías líricas y jocoserias. Su autor don José Joaquín Benegasi y Luján, señor de los Terreros y Valdeloshielos, regidor perpetuo de la ciudad de Loja, quien las dedica al excelentísimo señor marqués de Villena, duque de Escalona, conde de San Esteban de Gormaz, caballero del insigne orden del Toisón, etc. En Madrid, en la imprenta de José González; vive en la calle del Arenal.

Benegasi y Luján, J. J. (1746) Obras líricas jocoserias que dejó escritas el señor don Francisco Benegasi y Luján, caballero que fue del orden de Calatrava, gobernador y superintendente general de Alcázar de San Juan, Villanueva de los Infantes y Molina de Aragón, del consejo de su majestad, en el de Hacienda, regidor perpetuo de la muy noble ciudad de Loja, patrono de la capilla que en el real monasterio de san Jerónimo de esta corte fundó la señora doña María Ana de Luján, etc. 
Van añadidas algunas poesías de su hijo, don José Benegasi y Luján, posteriores a su primer tomo lírico, las que se notan con esta señal *. En Madrid, en la oficina de Juan de san Martín y a su costa; se hallará en su librería, calle de la Montera, donde se vende el Mercurio.

Benegasi y Luján, J. J. (1746/2018) “La campana de descasar", en Obras líricas jocoserias que dejó escritas el señor don Francisco Benegasi y Luján [...]. En Madrid, en la oficina de Juan de san Martín y a su costa; se hallará en su librería, calle de la Montera, donde se vende el Mercurio/"La campana de descasar, entremés de José Joaquín Benegasi y Luján: comentario y edición anotada", Mata Induráin, C. (ed.), Hipogrifo, 6.2, 639-655: https://www.revistahipogrifo.com/index.php/hipogrifo/article/view/532 (última consulta: 10/12/2021).

Benegasi y Luján, J. J. (s.f., Años 40?/2020) [Anónima] Comedia (que no lo es) burlesca, intitulada Llámenla como quisieren. Su autor ella lo dirá. Y se hallará donde la encuentren, y será en la imprenta y librería de Juan de san Martín, calle del Carmen, donde se hallarán otros papeles curiosos escritos por el mismo autor. En Madrid, por Juan de San Martín / "Llámenla como quisieren. Comedia burlesca de José Joaquín Benegasi y Luján. Edición, estudio preliminar y notas", Mata Induráin, C. (ed.), en Mata Induráin, C. (coord.), Antología de la literatura burlesca del Siglo de Oro, 8. Comedias burlescas, Pamplona, Servicio de Publicaciones de la Universidad de Navarra, 617-696.

Benegasi y Luján, J. J. (1750) Vida del portentoso negro san Benito de Palermo, descrita en seis cantos, jocoserios, del reducidísimo metro de seguidillas, con los argumentos en octavas, por don José Joaquín Benegasi y Luján. En Madrid, en la imprenta de Juan de San Martín. Se hallará en su librería, calle de la Montera, con las demás obras del autor.

Benegasi y Luján, J. J. (1752) Poesías líricas, y entre estas, la "Vida del glorioso san Dámaso, pontífice máximo, natural de Madrid, martillo de la herejía, diamante de la fe, crisol de la castidad y especialísimo abogado de los perseguidos con falsos testimonios, escrita en 
redondillas jocoserias". Su autor don José Joaquín Benegasi y Luján, señor de los Terreros y Valdeloshielos, regidor perpetuo de la ciudad de Loja y patrono de la capilla que en el Real monasterio de san Jerónimo de esta corte fundó la señora doña Mariana de Luján, etc. En Madrid, por Juan de Zúñiga.

Benegasi y Luján, J. J. (1752b, reed.) Vida del portentoso negro san Benito de Palermo, descrita en seis cantos jocoserios, del reducidísimo metro de seguidillas, con los argumentos en octavas, por don José Joaquín Benegasi y Luján. Con licencia en Madrid y reimpreso en El Puerto de Santa María, por Francisco Vicente Muñoz, impresor mayor de la ciudad, y se hallará en su librería, en la calle de Luna.

Benegasi y Luján, J. J. (1754) Fama póstuma del reverendísimo padre fray Juan de la Concepción, escritor de su sagrada religión de carmelitas descalzos, calificador de la Suprema, secretario general, consultor del serenísimo señor infante cardenal, de la Real Academia de la Lengua Española, etc. Escribíala en octavas don José Joaquín Benegasi y Luján, regidor perpetuo de la ciudad de Loja, etc. También se incluye el célebre poema que compuso dicho reverendísimo con el título de Escuela de Urania y un indice de varias obras suyas, impresas y manuscritas, etc. Se dedica a mi señora doña Raimunda Biempica y Sotomayor, etc. En Madrid, en la imprenta del Mercurio, por José de Orga, impresor. Se hallará en casa de don Francisco González Clemente, frente de la Cárcel de la Corte, y los otros dos papeles que se previenen el índice.

Benegasi y Luján, J. J. (1755) Con el motivo del terrible temblor de tierra sucedido en el día de Todos los Santos de este año de 1755 escribió don José Joaquín Benegasi y Luján a su amigo el reverendo padre fray Juan Carrasco, religioso trinitario calzado, el siguiente soneto. En Madrid, en la imprenta y librería de José García Lanza.

Benegasi y Luján, J. J. (1755b) Descripción del terremoto según se experimentó en la villa de Herencia el día 1 de noviembre de este año de 1755 a las diez del día. Compuesto a impulsos del desengaño, para mayor escarmiento, por don José Joaquín Benegasi y Luján en estas endechas endecasílabas. En Madrid, en la oficina de José de Orga, 
impresor, calle de Bordadores, junto a la Casa Profesa. Se hallará en la librería de José Orcel, a la entrada de la calle de la Montera.

Benegasi y Luján, J. J. (1755c) Papel en prosa y diferentes metros celebrando los sobresalientes talentos, elevadas prendas y acertadísima conducta de nuestro soberano. Escribíale al señor marqués de la Olmeda, comendador de Villarrubia de Ocaña, en la orden de Santiago, etc., su antiguo apasionado don José Joaquín Benegasi y Luján, señor de los Terreros y Valdeloshielos, regidor perpetuo de la ciudad de Loja. En Madrid, por José de Orga.

Benegasi y Luján, J. J. (1760) Descripción festiva de la suntuosa carrera y reales funciones con que esta imperial y coronada villa ha celebrado la plausible entrada y exaltación al trono de nuestros católicos monarcas, los señores don Carlos III y doña María Amalia, en los días 13, 14, 15 y 19 de julio de este año de 1760. Escribíala en seguidillas y con la introducción en octavas jocosas don José Joaquín Benegasi y Luján, regidor perpetuo de la ciudad de Loja. Se hallará en Madrid, en la librería de José Matías Escribano, frente de San Felipe el Real.

Benegasi y Luján, J. J. (1760?) Obras métricas que a distintos asuntos, así serios como festivos (aumentada en más de la mitad en esta segunda impresión) escribía fray don José Joaquín Benegasi y Luján, canónigo reglar de nuestro gran padre san Agustín, del hábito de san Antonio Abad. Dedicado al excelentísimo señor duque de Arcos y Caños, etc. En Madrid, en la imprenta de Miguel Escribano, calle Angosta de san Bernardo; se hallará, junto a otras obras del autor, en la librería de José Matías Escribano, frente a las gradas de san Felipe el real.

Benegasi y Luján, J. J. (1760?b, reed.) Papel en prosa y diferentes metros celebrando los sobresalientes talentos, elevadas prendas y acertadísima conducta de nuestro soberano. Escribíale al señor marqués de la Olmeda, comendador de Villarrubia de Ocaña, en la orden de Santiago, etc., su antiguo apasionado don José Joaquín Benegasi y Luján, señor de los Terreros y Valdeloshielos, regidor perpetuo de la ciudad de Loja. En Madrid, en la imprenta de Miguel Escribano, calle Angosta de san Bernardo. Se hallará este papel y otro del mismo autor intitulado Rasgo métrico en las librerías de José Matías Escribano y en la de Juan Pérez, frente de san Felipe el Real. 
Benegasi y Luján, J. J. (1760b/2015) Papel nuevo. Benegasi contra Benegasi: escrito a un amigo y haciendo crítica de la Descripción de las fiestas que publicó, con cuyo motivo se tocan en el principio otros asuntos. Con licencia, en Madrid, en la imprenta de Juan de San Martín, calle de la Montera, donde se hallará con las demás obras del autor/ Benegasi contra Benegasi, Padilla Aguilera, T. (ed.), PHEBO, Universidad de Córdoba: http://www.uco.es/investigacion/ proyectos/phebo/sites/default/files/benegasi_contra_benegasi. pdf (última consulta: 10/12/2021).

Benegasi y Luján, J. J. (1761, reed.) Comedia (que no lo es) burlesca, intitulada Llámenla como quisieren. Su autor ella lo dirá, y por si lo calla: don José Joaquín Benegasi y Luján, etc. Se incluye al fin de ella el sainete de El Amor casamentero. Segunda impresión. En Madrid, en la imprenta de Francisco Javier García, calle de los Capellanes. Se hallará en la librería de José Matías Escribano, frente a las gradas de San Felipe el Real.

Benegasi y Luján, J. J. (1763, reed.) Vida del glorioso san Dámaso, pontífice máximo, martillo de la herejía, diamante de la fe, crisol de la castidad y especialísimo abogado de los perseguidos con falsos testimonios. Escribíala en redondillas jocoserias fray don José Joaquín Benegasi y Luján, canónigo reglar de nuestro gran padre san Agustín, del hábito de san Antonio Abad, en su real casa de esta corte. Sale aumentada y corregida en esta segunda impresión por el mismo autor. En Madrid, en la imprenta de Miguel Escribano, calle Angosta de san Bernardo. Se hallará, con otras obras del autor, en la librería de José Matías Escribano, frente de San Felipe el Real.

Benegasi y Luján, J. J. (1763b, reed.) Vida del portentoso negro san Benito de Palermo, descrita en seis cantos jocoserios, del reducidísimo metro de seguidillas, con los argumentos en octavas, por fray don José Joaquín Benegasi y Luján, canónigo reglar de nuestro gran padre san Agustín, del hábito de san Antonio Abad. En Madrid, en la imprenta de Miguel Escribano, calle Angosta de San Bernardo. Se hallará, con otras obras del autor, en la librería de José Matías Escribano, frente de San Felipe el Real. 
Benegasi y Luján, J. J. (1779, reed.) Vida del portentoso negro san Benito de Palermo, descrita en seis cantos jocoserios, del reducidísimo metro de seguidillas, con los argumentos en octavas, por fray don José Joaquín Benegasi y Luján, canónigo reglar de nuestro gran padre san Agustín, del hábito de san Antonio Abad en su real casa hospital de esta corte. En Madrid, en la imprenta de don Antonio Pérez de Soto, impresor de la Real Biblioteca. A costa de la Real Compañía de Impresores y Libreros del Reino.

Bourdieu, P. (2006) Las reglas del arte: génesis y estructura del campo literario, Barcelona, Anagrama.

Buiguès, J.-M. (2019) “Modelos icónicos de las imágenes de la inspiración del autor religioso (Edad Media - Siglo xviII)", en Özmen, E. y Padilla Aguilera, T. (coord.), El autor en la modernidad, monográfico de Theory Now, vol. 2, 1, 10-32.

Cárdenas Luna, R. (2019) "Retrato y estatus. Una aproximación a la imagen de autor", en Özmen, E. y Padilla Aguilera, T. (coord.), El autor en la modernidad, monográfico de Theory Now, 2, 1, 135-158.

Deacon, P. (1999) “El autor esquivo en la cultura española del siglo xvirl. Apuntes sobre decoro, estrategias y juegos", Dieciocho, 22, 2, 213-236.

Espinosa, P. de (1605) Primera parte de las Flores de poetas ilustres de España, dividida en dos libros, Valladolid, Luis Sánchez.

Étienvre, J-P. (2004) “Primores de lo jocoserio", Bulletin Hispanique, 106, 1, 235-252.

Infantes, V. (2006) Del libro áureo, Madrid, Calambur.

Lafuente Ferrari, E. (1935) Los retratos de Lope de Vega, Madrid, Imprenta Helénica.

Lefevere, A. (1997) Traducción, reescritura y manipulación del canon literario, Salamanca, Colegio de España.

Lopez, F. (2003) “Los editores”, en Infantes, V., Lopez, F. y Botrel, J.-F. (dir.), Historia de la edición y de la lectura en España, 14751914, Madrid, Fundación Germán Sánchez Ruipérez, 358-367.

Lucía Megías, J. M. (2013) Catálogo de la exposición Lope en la piel de Brugalla, Madrid, Memoria de Madrid. Biblioteca digital: 
http://www.memoriademadrid.es/buscador.php?accion=VerFicha\&id=118196 (última consulta: 10/12/2021).

Maier Allende, J. (2018) “Jerónimo Antonio Gil”, Diccionario Biográfico Español (DB e), Real Academia de la Historia: http://dbe.rah.es/biografias/21967/jeronimo-antonio-gil (última consulta: 10/12/2021).

Maravall, J.A. (2002) Antiguos y modernos. La idea de progreso en el desarrollo inicial de una sociedad, Barcelona, Alianza, 1966.

Mata Induráin, C., ed. (2007) "Llámenla como quisieren, de José Joaquín Benegasi y Luján, comedia burlesca del siglo xviII", Oppidum: cuadernos de investigación, 3, Segovia,189-220.

Mata Induráin, C. (2018) “'Diome Apolo mi destino / para lo jocoso solo': la poesía festiva de José Joaquín Benegasi y Luján", en Bègue, A. y Mata Induráin, C. (eds.), Hacia la Modernidad. La construcción de un nuevo orden teórico literario entre Barroco y Neoclasicismo, Vigo, Academia del Hispanismo, 97-109.

Mata Induráin, C., ed. (2018) "La campana de descasar, entremés de José Joaquín Benegasi y Luján: comentario y edición anotada", Hipogrifo, 6.2, 639-655: https://www.revistahipogrifo.com/index.php/hipogrifo/article/view/532 (última consulta: 10/12/2021).

McKenzie, D. F. (1986) Bibliography and the sociology of texts, London, The British Library.

Molina Martín, Á. (2016) “Retratos de españoles ilustres con un epítome de sus vidas orígenes y gestación de una empresa ilustrada", Archivo español del arte, LXXXIX, 353, 43-60.

MolL, J. (1994) De la imprenta al lector: estudio sobre el libro español de los siglos xvi al xviII, Madrid, Arco.

Padilla Aguilera, T. (2019) "Benegasi y la fiesta de la llegada al trono de Carlos III", Cuadernos de Estudios del Siglo xviII, 29, 363-394.

Padilla Aguilera, T. (2019b) “J. J. Benegasi y Luján en sus impresos: la construcción de un perfil poliédrico", Cuadernos Dieciochistas, 20, 527-559.

Padilla Aguilera, T. (2019c) “José Joaquín Benegasi y Luján (1707-1770): perfil vital", Cuadernos de Ilustración y Romanticismo, $25,359-444$. 
Padilla Aguilera, T. (2021) "José Joaquín Benegasi y Luján en tres textos del periodo de senectute: cotejo material y contextual", Rassegna iberistica, 44, 115, 9-26.

Padilla Aguilera, T. (2021b) "Papel nuevo. Benegasi contra Benegasi: la autoafirmación como estrategia de mercado", en Comellas, M. (coord.), "Controversias ilustradas", monográfico de Anejos de Dieciocho, 8, 309-334.

Padilla Aguilera, T. (2023, en prensa) "José Joaquín Benegasi y Luján y la Fama Póstuma de fray Juan de la Concepción: estrategia editorial, red de sociabilidad y autoconstrucción del yo", Bulletin Hispanique.

Pérez de Montalbán, J. (1636) Fama póstuma a la vida y muerte del doctor frey Lope Félix de Vega Carpio y elogios panegíricos a la inmortalidad de su nombre, Madrid, Imprenta del Reino.

Pérez Magallón, J. (2002) Construyendo la modernidad: la cultura española en el "tiempo de los novatores" (1675-1725), Madrid, CSIC.

Rozas, J. M. (1984) “Lope contra Pellicer: historia de una guerra literaria", en Aurora Egido, A. (coord.), La literatura en Aragón, Zaragoza, Tipo Línea, 67-100.

Rozas, J. M. (1990) "El ciclo de senectute", en Rozas, J. M., Estudios sobre Lope de Vega, Madrid, Cátedra, 73-133.

Ruiz Pérez, P. (2012) “Para una bibliografía de José Joaquín Benegasi y Luján. Hacia su consideración crítica", Voz y letra: Revista de literatura, 23, 1, 147-169.

SÁnchez Espinosa, G. (2009) "La producción editorial del Despotismo Ilustrado: la Imprenta Real", en Ribagorda, J.M. (ed.), Imprenta Real: fuentes de la tipografía española, Madrid, AECID, Real Academia de Bellas Artes de San Fernando, 72-85.

SÁnChez Jiménez, A. (2006) Lope pintado por sí mismo: mito e imagen del autor en la poesía de Lope de Vega Carpio, Woodbridge, Tamesis.

SÁnChez Jiménez, A. (2011) El pincel y el Fénix: pintura y literatura en la obra de Lope de Vega Carpio, Madrid, Iberoamericana; Frankfurt am Main, Vervuert. 
SÁnchez Jiménez, A. (2018) Lope de Vega: el verso y la vida, Madrid, Cátedra.

Tubau, X. (2007) Una polémica literaria: Lope de Vega y Diego de Colmenares, Madrid, Iberoamericana/Frankfurt am Main, Vervuert.

Vega Carpio, F. L. de (1598) La Arcadia, Madrid, Librerías de Castillo.

Vega Carpio, F. L. de (1604/1733) El peregrino en su patria, de Lope de Vega Carpio dedicado a don Pedro Fernández de Córdoba, marqués de Priego, señor de la casa de Aguilar, Sevilla, Clemente Hidalgo/ El peregrino en su patria, de fray Lope de Vega Carpio, Madrid, Francisco Martínez Abad.

Vega Carpio, F. L. de (1630) Laurel de Apolo con otras rimas [...], Madrid, Juan González.

Vv. AA. (2021) Gazeta (1661-1959). Buscador de la Gaceta de Madrid. Madrid, Agencia Estatal Boletín Oficial del Estado: https://www.boe.es/buscar/gazeta.php (última consulta:10/12/2021). 
